\title{
Development of 2013 Curriculum Learning Model based on Trigger Powerpoint Media to Improves Students' Creative Thinking Skill
}

\author{
A. Rahadyan ${ }^{1}$, EAR Pinahayu ${ }^{2}$, I Kurniawan ${ }^{3 *}, \mathrm{~N}$ Dwitiyanti $^{4}, \mathrm{R}_{\text {Abdillah }}^{5}$ \\ 1,2,3,4,5 UniversitasIndraprasta PGRI, Jakarta , Indonesia \\ *Corresponding author:inkur.master@gmail.com,
}

\begin{tabular}{l}
\hline a r t i c l ein f o \\
\hline How to cite this article: \\
Rahadyan, A., et al.. (2019). Development of \\
2013 Curriculum Learning Model based on \\
Trigger Powerpoint Media to Improves Students' \\
Creative Thinking Skill. Eduma: Mathematics \\
Education Learning and Teaching. 8(2), 1-9, \\
doi: http://dx.doi.org/10.24235/eduma.v8i2.5016
\end{tabular}

Article history:

Received: 08 22, 2019

Accepted: 11 22, 2019

Published: 12 05, 2019

Copyright $\odot 2019$ by author (s) and EduMa: Mathematics Education Learning and Teaching under the Creative Commons Attribution-ShareAlike 4.0 International License.

\begin{abstract}
Development of 2013 Curriculum Learning Model based on Trigger Powerpoint Media to Improves Students' Creative Thinking skill. This research is to develop 2013 curriculum learning model using trigger Microsoft power point. This is an innovative learning model in order to enhance students' creative thinking skill in mathematics problem solving. The research method is RND with qualitative research using data collecting techniques such as cheque list, observation, questioner, and problem-solving task. The sample of this research is primary students. The processes of developing this model are (a) initial investigation phase is to study literatures and collect the information, (b) design phase is to design the syntax of this model and create the lesson plans, worksheets, and learning materials, (c) realization phase is to do the syntax of this model and the learning materials, and (d) trial, evaluation, and revision phase is the syntax and the learning materials are validated by some validators, do some revisions, then these are evaluated or tried out in a class. This research results a valid, effective, and practical learning model that is able to enhance students' creative thinking skill in mathematics problem solving. Thus, the 2013 curriculum using trigger Microsoft power point is a learning model that can be applied in primary school related to 2013 curriculum. .
\end{abstract}

Keywords :

Curriculum 2013; Powerpoint; Creative Thinking Skill 


\section{INTRODUCTION}

Mathematics is a subject at the school level presented using symbols, terms, formulas, diagrams, tables and can also be viewed as a language. Mathematics has various completeness as a language such as thinking aids, a tool for finding patterns, solving problems, and also generating conclusions. But mathematics is an invaluable tool for conveying ideas clearly, accurately, and concisely (Baiduri, 2014). Problem solving is a dependent aspect of mathematics learning. Problems will exist when students have goals, strive for goals and find meaning in the process of reaching those goals (Bey, 2014). Thus, the problems that arise when reaching the goal must be well analyzed so that it can be completed and obtained the best solution. Based on the above description, it can be concluded that it takes effort in thinking and generated ideas so that it can solve the problem. Based on these problems, it needs an effective and innovative learning model. Therefore, it is necessary to develop an innovative learning model that can improve students' creativity in solving math problems.

Reveals that mathematical
thinking in solving mathematical problems was called as creative thinking (Lince, 2016). If in solving math problems routine, and students could complete in a manner different from that taught by teachers in the classroom, then these students could be said to be creative in mathematics. Proposed that there were four competencies to assess creative thinking, such as fluency, flexibility, originality, and elaboration (Maharani, 2014). Open ended problems and problem posing were presented could influence the capability of creative thinking's children in mathematics.Liliasari et al. suggest that the students' thinking ability to become active learners and use their higher thinking skills such as ability to think creatively through analysis, synthesis, evaluation and reflection in solving a given problem can be stimulated by using interactive multimedia learning (Liliasari, Supriyanti \& Hana, 2016). Using computer as interactive multimedia can be good choice to present learning material, so it will be able to support students in visualizing the problem and finding the solution.

Suggests that computers can be involved in creative work examining four categories of human-computer interaction to promote creativity (Lubart, 2005). A classification based on four categories is proposed: computer may facilitate the managing of creative work, communicating between individuals collaborating on creative projects, enhancing creativity, and producing the creative act through integrated humancomputer cooperation. The study explored the possibility of developing creative thinking among students through information and communication technology (ICT), their study showed positive results on creative thinking through a number of composition tasks of creativity model which was used in three associated activities, namely, problem solving, creative integration, and social interaction (Wheeler, Waite \& Bromfield, 2002). This study represents some new results about the nature of creativity associated with the computer and educational technology practiced in the learning environment and the use of computer-enhanced study methods in the development of creative thinking. The effects of using computers to enhance solving problems in mathematics for the disable students, unbelievable conclusion were informed that using computer 
technologies would increase disable students high-order thinking skills and attract them to deal with complex mathematics problems (Babbitt \& Miller, 1996). The strength of the computer and its associated modern technologies influence creativity, and it is predicted to become highly increasing and it is very hard to keep the technological development without the use of the computer, as people are now becoming aware of the importance of computers and its applications (Mokaram, Al-Shabatat, Fong, \& Abdallah, 2011).

PowerPoint is part of the Information and Communications Technology (ICT) program developed by Microsoft in 1987. PowerPoint gives the user the opportunity to incorporate visual and auditory aspects to a presentation. It permits variety of manipulations by editing or text modification, removal of existing slides and addition of new slides to make lesson more organized and flexible. PowerPoint presentations can be regarded as a good instructional medium and a key for facilitating an effective teaching-learning process (Gambari, Yusuf, \& Balogun, 2015). PowerPoint should be recognized as a new communication medium that is fundamentally changing the nature and dynamic of how teachers teach (Craig \& Amernic, 2006). In a classroom learning model that uses the 2013 curriculum with a scientific approach, the 2013 curriculum learning model contains $5 \mathrm{M}$ activity syntax that is observing, asking, trying, associating, and communicating. In development research there are three criteria to determine the quality of model and learning device that is valid, practical, and effective (Baiduri, 2014). Scientific approach and stresses on authentic evaluation on mathematic learning 2013 curriculum will stimulate student's knowledge in responding the environment (Sutama, Narimo, \& Samino, 2015).

Based on that background, the 2013 curriculum-based learning model of trigger powerpoint is part of a mathematical problem-solving activity that can be developed. In addition, students'creative thinking ability has a role in solving mathematical problems and intuition can facilitate students' creative thinking ability. Thus, the researchers intend to conduct further research on the development of the 2013 curriculum learning model based on trigger powerpoint media in order to improve students' creative thinking ability in solving math problems. This research will develop a 2013 curriculum learning model based on trigger powerpoint media in solving mathematical problems and supporting tools such as teaching materials, lesson plans, worksheets, and assignment sheets that are valid, practical, and effective in improving students' creative thinking ability.

\section{METHODS}

The study was conducted from February 2018 to July 2018 in one of the primary schools in Jakarta in the even semester of the academic year 2017/2018. This research is a development research (R\&D). R\&D basically consists of two main objectives, namely developing the product and testing the effectiveness of the product in achieving the goal. The product developed and tested for its effectiveness in this research activity is the development of an intuitive-based model to improve students' creative thinking ability in solving mathematical problems that meet valid, practical, and 
effective criteria. In the development of this model also developed learning tools including lesson plan, worksheets based on flash media and assignment sheets and other supporting instruments. Data collection in this study was conducted in various ways, namely by check list, observation, questionnaire, student worksheets obtained from research subjects involved in it.

Development of learning model based on trigger powerpoint media

Referring to the curriculum in Indonesia, the learning model used in this research is an appropriate learning model in the 2013 curriculum. This learning model can be developed and modified into a learning model of 2013 curriculum based on trigger powerpoint media. The syntax of 2013 curriculum learning model based on trigger powerpoint media that is expected to improve the ability of creative thinking is as follows: (a) teachers prepare students psychically and physically to follow the learning process; (b) as apperception, students are invited to recall the previous materials; (c) teachers convey the motivation and learning objectives to be achieved; (d) teachers divide students heterogeneously into groups of two; (e) teacher gives student worksheet on material to each group for discussion and questioning in group, 5M activities are included in this phase:observing, students are directed to pay attention to student worksheets created in the form of a given trigger powerpoint medium;asking, students were given a stimulus on questions related to student worksheets.

While the other students are given the opportunity to respond to questions his friend;exploring and associating, students in each group are given the opportunity to understand the given problem; and communicating, students are given the opportunity to communicate in the form of conclusions from the given problem; (f) after group activities are completed, individually students are given problems such as student duty sheets to work on and teachers as facilitators guide students with the following steps:preparatory stage, students understand the given problem;incubation stage, students explore the existing problems then think about how the solution;illumination stage, students convey ideas to existing problems, then students are asked to solve problems with existing ideas or ideas until answers are obtained. Incubation stage and illumination stage can take place over and over again; andverification stage, students verify answers, so students are optimistic about the answers given. The teacher guides the students who are still having trouble solving the problem; (g) students with teacher help summarize the various ways or strategies to solve real problems in the given lesson; and (h) teachers provide homework, end the learning activities with greetings and provide motivation in learning and never give up in learning.

\section{RESULTS AND DISCUSSIONS}

Results of validations.

The validation sheet is intended to get data about the validity of the model and learning tools. The modified validation sheet is validated by three validators that match the field of learning model development. The designed validation sheet consists of:

The validation sheet of the lesson plans.

Based on the validation of the lesson plan sheet, the rating criteria of the sheet has an average of 3,209. Therefore, 
the sheet is said to meet the valid criteria. In addition to the validation results, there are some validator suggestions that are important to note so that based on the assessment and suggestions are then evaluated. The evaluation results are revised. Revision details include:(a) in the preliminary and core activities have been adapted to the material or included material; (b) there is a synchronization between the basic competencies and the indicators; and (c) all mathematical notations or symbols are written in italics on learning materials.

The validation sheet of worksheets.

Based on the validation of the above worksheets, the rating criteria of the sheet have an average of 3.28. Therefore, the sheet is said to meet the valid criteria. In addition to the validation results, there are some validator suggestions that are important to note so that based on the assessment and suggestions are then evaluated. The evaluation results are revised. Revision details include: fractional writing is clearly legible.

The validation sheet of assignment sheets.

The assignment sheets validation and revision result consists of two parts: assignment sheets validation and assignment sheets scoring guidance.(a) Assignment sheets validation results;
Based on the validation of the sheet about the criteria of assessment of the sheet has an average of 3.19. Therefore, the sheet is said to meet the valid criteria. In addition to the validation results, there are some validator suggestions that are important to note so that based on the assessment and suggestions are then evaluated. The evaluation results are revised. The revised description is that the questioning is concerned with the degree of difficulty and complexity.(b) Assignment sheets scoring validation results; Based on the assignment sheets scoring validation results, the sheet rating criteria have an average of 3.18. Therefore, the sheet is said to meet the valid criteria. In addition to the validation results, there are some validator suggestions that are important to note so that based on the assessment and suggestions are then evaluated. The evaluation results are revised. Description of the revision made is written symbol math read.

Results of field trials

To develop a media-based learning model of this powerpoint trigger was conducted two field trials. These trials, evaluations and revisions were made twice to obtain a media-based trigger powerpoint learning model with valid, practical, and effective criteriaestablished. Here is an average of test scores 1 and 2.

Table 1. Average Results of Tests 1 and 2

\begin{tabular}{|c|c|c|}
\hline \multirow[t]{2}{*}{ Criteria } & \multicolumn{2}{|c|}{$\begin{array}{c}\text { Average Results of } \\
\text { Tests }\end{array}$} \\
\hline & Test 1 & Test 2 \\
\hline Lesson plan & $3,22 \%$ & $3,31 \%$ \\
\hline $\begin{array}{l}\text { Student positive response to assignment } \\
\text { sheets }\end{array}$ & $76,65 \%$ & $78,35 \%$ \\
\hline $\begin{array}{l}\text { Student negative response to assignment } \\
\text { sheets }\end{array}$ & $68,30 \%$. & $65,20 \%$. \\
\hline
\end{tabular}


In the analysis of trials 1 and 2 there are three assignment sheets given to test the students' creative thinking ability level and whether in tests 1 and 2 it meets the criteria of effectiveness. The assessment rubric of creative thinking that is an adaptation was used to analyze the results of this assignment sheets test and adapted to the needs of the study (Sutama, Narimo \&Samino, 2015). The results of the analysis can be seen in Tables 2 and 3 below.

Table 2. Percentage of results of assignment sheetstest 1

\begin{tabular}{ccccccc}
\hline \multirow{2}{*}{$\begin{array}{l}\text { Levels } \\
\text { of }\end{array}$} & \multicolumn{2}{c}{ Assignment sheets1 } & \multicolumn{2}{c}{ Assignment sheets2 } & \multicolumn{2}{c}{ Assignment sheets3 } \\
\cline { 2 - 7 } creative & $\begin{array}{c}\text { No.1 } \\
(\%)\end{array}$ & $\begin{array}{c}\text { No.2 } \\
(\%)\end{array}$ & $\begin{array}{c}\text { No.1 } \\
(\%)\end{array}$ & $\begin{array}{c}\text { No.2 } \\
(\%)\end{array}$ & $\begin{array}{c}\text { No.1 } \\
(\%)\end{array}$ & $\begin{array}{c}\text { No.2 } \\
(\%)\end{array}$ \\
\hline 0 & 83,87 & 58,06 & 14,28 & 82,14 & 62,5 & 78,12 \\
1 & 19,35 & 38,71 & 82,14 & 17,86 & 34,37 & 24,14 \\
2 & 0 & 3,22 & 3,57 & 0 & 3,45 & 0 \\
3 & 0 & 0 & 0 & 0 & 0 & 0 \\
4 & 0 & 0 & 0 & 0 & 0 & 0 \\
\hline
\end{tabular}

Table 3. Percentage of results of assignment sheetstest2

\begin{tabular}{llllllc}
\hline \multirow{2}{*}{$\begin{array}{l}\text { Levels } \\
\text { of }\end{array}$} & \multicolumn{2}{c}{ Assignment sheets1 } & \multicolumn{2}{c}{ Assignment sheets2 } & \multicolumn{2}{c}{ Assignment sheets3 } \\
\cline { 2 - 7 } creative & No.1 & No.2 & No.1 & No.2 & No.1 & $\begin{array}{c}\text { No.2 } \\
(\%)\end{array}$ \\
\hline \multicolumn{1}{c}{$(\%)$} & 83,87 & 58,06 & 14,28 & 82,14 & 62,5 & 78.12 \\
1 & 19,35 & 34,71 & 82,14 & 17,86 & 31,35 & 24,14 \\
2 & 0 & 3,22 & 3,57 & 0 & 3,45 & 0 \\
3 & 0 & 3,22 & 0 & 0 & 3,45 & 0 \\
4 & 0 & 0 & 0 & 0 & 0 & 0 \\
\hline
\end{tabular}

\section{Discussions}

Validity of the learning model.

The results of the validation of learning tools which include the results of the validation of the lesson plan sheet have an average of 3.20. Likewise also with teaching materials

Obtained have an average of 3.13 and worksheet has an average of 3.28. As well as the results of the validation of the question sheet and assignment sheets scoring have an average of 3.19 and 3.18. Based on the results of research development that the learning tools have been declared valid. Learning devices are said to be valid because they have fulfilled all aspects of validity. This validity is determined by the assessment by the validator. Validity criteria aside from experts and practitioners stating that the learning tools in the intuition-based learning model can be applied in the classroom.The learning tools that fulfill validity are learning tools, one of which is based on strong theoretical rationales [4]. Practicality.

Based on the results of test 1 , the assessment criteria for learning feasibility are having an average of 3.22 so that observation of learning implementation meets the criteria of practicality. Whereas in the results of the trial 2, the 
assessment criteria for learning feasibility are having an average of 3.31 so that the observation of the implementation of learning also meets the criteria of practicality. The intuition-based learning model if it meets: (1) experts and practitioners state that the model of intuition-based learning and learning tools can be applied in the classroom and (2) based on the results of the study indicate that learning models based on powerpoint trigger media and learning tools can be applied in class (Wheeler, Waite, \& Bromfield, 2002). This is indicated by the level of success in implementing learning models based on powerpoint trigger media that has fulfilled the practical aspects

Effectiveness.

The criteria for effectiveness include: (a) student responses, response questionnaire sheets are applied to students and the results of the first test are the results of positive questions that provide a positive response obtained on average by $76.65 \%$. Furthermore, the results of negative questions that provide a positive response obtained an average of $68.30 \%$. Therefore, the results of the student response questionnaire on this trial 1 met the effective criteria. However, to ensure that the research data is valid or not, a second trial is carried out so that the results of positive questions can be obtained which give a positive response obtained an average of $78.5 \%$. Thus, the results of student response questionnaires on this trial 2 meet the effective criteria. Furthermore, the results of negative questions that provide a positive response are obtained by an average of $65.30 \%$. So, there is a match between the results of the study and expert opinion, Nieveen, about the learning tools in the learning model based on the powerpoint trigger media developed has fulfilled the effective aspects seen from students' responses; and (b) the assignment sheet test result for the improvement of creative thinking ability, based on the result of test 1 for assignment sheet test, it can be seen that in each test the percentage of students who have increased the creativity of the students have not met the criteria that have been set. Based on the results of the test, it can be concluded that from the results of creative thinking tests on assignment sheet 1 number 2 , assignment sheet 2 number 1 and assignment sheet 3 number 1 there are students who meet the level of flexibility thinking as well as in assignment sheet 2 students on average meet the level of thinking fluency of 82 , $14 \%$. Based on the results of the 2 nd trial, it can be concluded that from the results of creative thinking tests on assignment sheet 1 number 2 and assignment sheet 3 number 1 there are students who meet the level of thinking fluency and newness and on assignment sheet 2 students on average meet the level of thinking fluency of $82.14 \%$. If this is compared with the results of trial 1 then the results of trial 2 experienced a significant increase. Thus, it can be said that trial 2 has increased in the level of creative thinking skills. Based on this, the development of learning models and devices based on powerpoint trigger media meets the effective criteria.

Referring to the expert opinion,Nieveen, the development research has an indicator that determines that the learning model and learning tools are said to be effective if operationally the intuition learning model and learning aids provide results as expected (Nieveen, 1999). So there is conformity with the results of research on learning tools developed that have fulfilled the effective aspects obtained from student test results. 
Students have different thinking process. One way to solve this problem is by grouping them according to their level of creativity in order to respect each students and do not seeing them as similar (Awaludin, Kurniawan \& Hartuti, 2018).

\section{CONCLUSIONS}

Based on the results of model development, interpretation of research results, and data analysis that has been done, it can be concluded as follows: (a) the process of developing an intuitionbased learning model conducted in this study is a research on modification development that refers to a combination of the models proposed by Plomp and Borg \& Gall. The steps are explained as follows:the initial investigation stage is the stage of conducting studies and gathering information on learning theory; the design stage is the syntax design stage in the model and compile learning tools such as lesson plans, worksheets, and assignment sheets; the realization stage is an activity which realizes the syntax of the model and device into draft 1; and the testing, evaluation and revision stages are model and device syntax validated by several experts, then revised, then evaluated which is then tested in class. The first and second trials were conducted in the fourth grade of SD Negeri 01 Setu because the results were valid, practical, and effective, the final draft was obtained; and (b) the results of the development of learning model based on powerpoint trigger media are valid, effective, and practical learning models so that the learning model based on powerpoint trigger media is a learning model that can be applied to SD Negeri 01 Setu and in accordance with the 2013 curriculum.
Following are the steps in the model syntax learning based on media powerpoint trigger: (a) the teacher coordinates students both psychologically and physically in readiness in carrying out the learning process; (b) in the apperception session, the teacher invites students to review the material previously taught; (c) the teacher conveys the motivation and purpose of the learning to be carried out; (d) the teacher divides students heterogeneously in groups of two people; and (e) the teacher gives the worksheets on the material to each group for discussion and questioning within the group.

Activity $5 \mathrm{M}$ is found at this stage, namely: observing, students are directed to read or learn the worksheets given; asking, asks students to be given a stimulus to ask questions about the problems in the worksheet, while other students are given the opportunity to raise questions on other students; exploring and associating, it is expected that students in each group will understand the problems that have been given; and communicating, it is expected that students in the group can express the results of the problem conclusions in the worksheet. At the end of group activities, students areindividually faced with existing problems such as in a task sheet to do and we as teachers only as facilitators guide with the following steps: preparatory stage, students understand the given problem; incubation stage, students are given the opportunity to understand the problem and think of a solution to the problem; illumination stage, students are given the opportunity to provide input on existing problems, then students are asked to solve problems with ideas or ideas that exist until an answer is obtained. Incubation stageand 
illumination stagecan take place repeatedly; and verification stage, students are given the opportunity to verify the answers, so they are sure of the answers. The teacher guides students if they still have difficulties in solving problems. Students with the help of the teacher summarize various ways in strategies to solve real problems in the material.

\section{REFERENCES}

Awaludin, A. A. R., Kurniawan, I., \& Hartuti, P. M. (2018). Junior High School Student's Reflective Thinking Process In Problem Solving Viewed From Learning Creativity,". Jurnal Pendidikan Indonesia (JPI), 6(2), 154-162.

Babbitt, B. C., \& Miller, S. P. (1996). Using hypermedia to improve the mathematics problem-solving skills of students with learning disabilities. Journal of Learning Disabilities, 29(4), 391-401.

Baiduri, B. (2014). A Relational Thinking Process of Elementery School Students with High Capability. Journal of Educational and Developmental Psychology, 4(2), 24-34.

Bey, A. (2014). Developing skills resolution mathematical primary school students. International Journal of Education and Research, 2(10), 601-614.

Craig, R. J., \& Amernic, J. H. (2006). PowerPoint presentation technology and the dynamics of teaching. Innovative Higher Education, 31(3), 147-160.

Gambari, A. I., Yusuf, H. T., \& Balogun, S. A. (1930). Effectiveness of powerpoint presentation on students' cognitive achievement in technical drawing. Malaysian Online Journal of Educational Technology, 3(4), 1-12.
Liliasari, M., Supriyanti, S., \& Hana, M. N. (2016). Students'creative Thinking Enhancement by Using Interactive Multimedia of Redox Reaction. Jurnal Pengajaran MIPA, 21(1), 30-34.

Lince, R. (2016). Creative thinking ability to increase student mathematical of junior high school by applying models numbered heads together. Journal of Education and Practice, 7(6), 206-212.

Lubart, T. (2005). How can computers be partners in the creative process: classification and commentary on the special issue. International Journal of Human-Computer Studies, 63(4-5), 365369 .

Maharani, H. R. (2014). Creative thinking in mathematics: Are we able to solve mathematical problems in a variety of way. In International Conference on Mathematics, Science, and Education (pp. 120-125).

Mokaram, A. A. K., Al-Shabatat, A. M., Fong, F. S., \& Abdallah, A. A. (2011). Enhancing Creative Thinking through Designing Electronic Slides. International Education Studies, 4(1), 39-43.

Nieveen, N. (1999). Prototyping to reach product quality. In Design approaches and tools in education and training (pp. 125135). Springer, Dordrecht.

Sutama, S. Narimo, \& Samino. (2015). Management of Curriculum 2013 Mathemathic Learning Evaluation In Junior High School. Int. J. Educ., 7(3),164174

Wheeler, S., Waite, S. J., \& Bromfield, C. (2002). Promoting creative thinking through the use of ICT. Journal of Computer Assisted Learning, 18(3), 367-378 